\title{
Obstructive Disordered Breathing During Sleep in Patients with Spinal Cord Injury ${ }^{\star}$
}

\author{
H. W. Bonekat, DO, G. Andersen, R EEG T, J. Squires, MD \\ Departments of Pulmonary Medicine and Rehabilitative Medicine, Salt Lake City \\ Veterans Administration Medical Center and University of Utah Medical Center, Salt \\ Lake City, Utah, USA. (Dr. Bonekat is now associated with the Pulmonary Division, \\ University of California, Davis.)
}

\begin{abstract}
Summary
Little is known about respiration and sleep in spinal cord injured (SCI) patients, and yet they frequently have complaints related to sleep. Four SCI patients with various sleep complaints were evaluated with nocturnal polysomnography. All 4 had evidence of obstructive sleep apnea (disordered breathing). These findings suggest that obstructive sleep apnea may be contributing to disruptive sleep in SCI patients and may be responsible for many of their daytime symptoms.
\end{abstract}

Key works: Spinal cord injury; Sleep apnea; Respiration; Disordered breathing

A common complaint of spinal cord injured (SCI) patients is difficulty in sleeping. They frequently complain that their 'spasms' prevent them from sleeping soundly, and they have difficulty initiating and maintaining sleep. Others have significant depression, causing them to have restless sleep, frequently awaking in the early hours of the morning, and unable to go back to sleep. These patients are unable to exercise and take frequent naps during the day causing nocturnal insomnia. Another clinical concern in these patients is the possibility that disordered breathing (apnea/hypopnea) during sleep may be contributing to their disruptive sleep. In recent years a sleep apnea syndrome has been discovered which is frequently associated with nocturnal snoring, daytime somnolence, restless sleep and personality changes (Ingbar, 1985). Middle-aged males and post-menopausal females seem to be prone to obstructive disordered breathing during sleep and may suffer from this disorder. Obesity, sedative ingestion, and sleeping in the supine position are all factors which may aggravate the situation. Many SCI patients have similar complaints. They are sedentary and although able to be up in a wheelchair during the day, they may not start their daytime activities until late morning (Alvarez, 1981). They frequently have daytime sleepiness and may be 'grouchy' when

\footnotetext{
* Presented at the 1988 Annual Scientific Assembly of the American College of Chest Physicians held in Anaheim, California, USA.

Correspondence to: Dr H. W. Bonekat, University of California, Davis Medical Center, Division of Pulmonary Medicine, 4301 X Street-Professional Building, Sacramento, CA 95817, USA.
} 
awakened. These patients require various sedative medications and may have anthropometric profiles similar to patients with sleep apnea.

\section{Case reports}

Four consecutive SCI patients with sleep complaints were referred for evaluation of possible sleep disordered breathing. Each individual underwent nocturnal polysomnography during a night's sleep at the Salt Lake City VA Sleep Laboratory. Standard techniques were used for placement of electroencephalogram (EEG), electrooculogram (EOG), and submental electromyogram (EMG). Nasal and oral thermistors were positioned to detect airflow and oxyhaemoglobin saturation $\left(\mathrm{SaO}_{2}\right)$ was measured with an ear oximeter. Chest wall and abdominal movements were recorded with a respiratory inductance vest (Respitrace) and EKG electrodes monitored heart rate.

The commonly accepted polysomnographic criteria for clinical sleep apnea has been arbitrarily defined as 5 apneas per hour or 30 or more apneic episodes with a duration of at least 10 seconds during a night's sleep. However, many authors feel the degree of nocturnal $\mathrm{O}_{2}$ desaturation is an essential measure in addition to the number of apneic events, in diagnosing sleep apnea (Kales, 1987; Moran, 1985; Suratt, 1983). Therefore, we accepted only those apneic events associated with $4 \%$ or more desaturation from baseline. All of our patients had a baseline $\mathrm{O}_{2}$ saturation awake of 93 to $94 \%$.

\section{Patient 1}

A 52-year-old man who suffered a spinal cord injury at the C5-C6 level secondary to a motor vehicle accident in 1984. He underwent extensive rehabilitation for 8 months and his hospitalisation was complicated by a deep venous leg thrombosis and pulmonary embolism. He was discharged using an electric wheelchair. Medications included Tegretol and Dilantin. Two years later he was referred for sleep evaluation from our Spinal Cord Clinic with symptoms of daytime somnolence, snoring and frequent awakenings.

Nocturnal polysomnography (NPSG) was carried out for a duration of 5 hours. The patient slept supine and periodic snoring was evident during sleep. Baseline $\mathrm{O}_{2}$ saturation awake was 93 to $94 \%$. While awake, the patient was noted to have paradoxical motion of the ribcage but airflow did not appear to be compromised. During early NREM (nonREM) stage sleep, mild obstructive sleep apnea was noted, associated with $\mathrm{O}_{2}$ desaturation. During REM stage sleep further $\mathrm{O}_{2}$ desaturations occurred, as airflow was minimal with recorded desaturations as low as $76 \%$. The patient awakened 3 times during the sleep study to have his bladder emptied.

\section{Comments}

Patient 1 has paradoxical inspiratory retraction of his ribcage which is related to denervation of his respiratory muscles secondary to his spinal cord injury. It appears to be worsened during sleep, and during REM stage sleep severe obstructive sleep apnea is present. His obstructive disordered breathing may be augmented by the supine position, however, this is the only position in which he can comfortably sleep. His restless sleep may also be related to bladder distension. 


\section{Patient 2}

A 70-year-old man sustained a spinal cord injury at the C5 level secondary to a fall from a horse 7 years ago. The patient has hypertension and was referred for evaluation of his inability to sleep on his left side due to neck pain. He snores at night and naps in his wheelchair, usually when reading. His medications included clonidine, Benadryl, Dilantin, and baclofen.

Nocturnal polysomnography was carried out for approximately 5.5 hours duration. Baseline $\mathrm{O}_{2}$ saturation awake was $93 \%$. When the patient slept on his right side there was some evidence of periodic breathing with intermittent paradoxical motion of the abdomen but appropriate expansion of the ribcage, suggesting that ribcage innervation was intact. No obstructive breathing was noted. However, in the supine position, obstructive disordered breathing was associated with desaturations as low as $78 \%$ during NREM stage sleep. During REM stage sleep, more prolonged episodes of obstructive sleep apnea were noted, with apneic episodes lasting as long as 70 seconds with desaturations as low as $61 \%$. During these obstructive events, the electrocardiogram revealed a relative bradycardia which improved with cessation of airflow obstruction.

\section{Comments}

Patient 2 has significant obstructive disordered breathing, especially in the supine position. Obstructive breathing was not present during sleep in the lateral position. Unfortunately, because of neck discomfort, it is hard for this patient to avoid the supine position during sleep. He has significant $\mathrm{O}_{2}$ desaturation during REM stage sleep.

\section{Patient 3}

A 46-year-old man sustained a spinal cord injury at the C5-C6 level secondary to an automobile accident in 1960. He complains of daytime somnolence and fitful sleep. Medications include baclofen.

Nocturnal polysomnography was carried out for a little over 5 hours duration. Baseline $\mathrm{O}_{2}$ saturation awake was $94 \%$. Awake, the patient exhibited paradoxical motion of his ribcage but airflow was unimpeded. Obstructive disordered breathing was noted both in the lateral and supine positions. This was associated with significant $\mathrm{O}_{2}$ desaturation, especially during REM stage sleep, with desaturations as low as $56 \%$ being recorded. Interestingly, this patient had numerous tooth-grinding (bruxism) episodes during sleep which seemed to be triggered by his frequent microarousals related to his post-obstructive breathing.

\section{Comments}

Patient 3 has evidence of significant obstructive disordered breathing during sleep associated with desaturation (Figure 1). The obstructive breathing was present in both lateral and supine positions, but was most prominent while supine. A recent paper in the literature (Phillips, 1986) alluded to the fact that tooth-grinding (TG) during sleep may be associated with obstructive sleep apnea and that sleep position may also play a role. Our patient seemed to have just as many TG episodes in the lateral position as he did supine.

\section{Patient 4}

A 38-year-old obese man was admitted to the hospital for paranoia schizophrenic behaviour. 

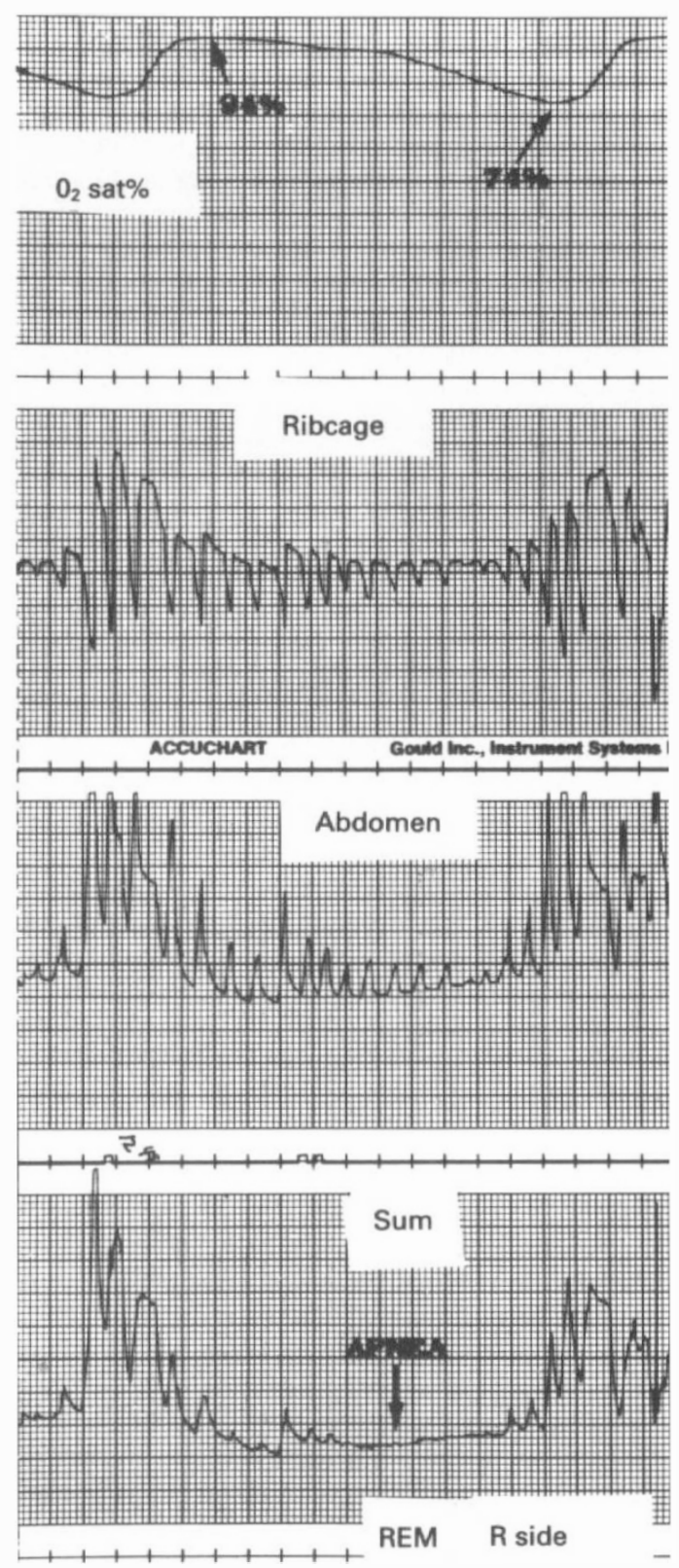

Figure Obstructive sleep apnea during REM stage sleep while in the right lateral position (Patient 3). During this recording of respiratory inductive plethysmography, paradoxical movements between the ribcage and abdominal compartments with minimal sum movement clearly define an obstructive apnea. Note the fall in $\mathrm{O}_{2}$ saturation from baseline (94\%) associated with the apneic event. 
He has been paraplegic (T12-L1) since a Vietnam shrapnel injury in 1967. In the hospital he developed chest pain, and during sleep was noted to have $\mathrm{O}_{2}$ desaturation via ear oximetry. Medications included Mellaril, Serax, and lithium.

Nocturnal polysomnography was carried out for 5 hours duration. Baseline $\mathrm{O}_{2}$ saturation awake was $94 \%$. Periodic snoring was noted during sleep. Obstructive sleep apnea was present while the patient slept in the supine position and was associated with $\mathrm{O}_{2}$ desaturation. Obstructive breathing was not apparent in the lateral position.

\section{Comments}

This patient has few daytime complaints but has documented obstructive sleep apnea associated with $\mathrm{O}_{2}$ desaturation during sleep. His ribcage motion while awake was normal.

\section{Results}

Table I Characteristics of 4 male SCI patients

\begin{tabular}{|c|c|c|c|c|c|c|c|}
\hline Patient & $\begin{array}{l}\text { Age } \\
\text { (years) }\end{array}$ & $\begin{array}{l}\text { Height } \\
(\mathrm{cm})\end{array}$ & $\begin{array}{l}\text { Weight } \\
\text { (kg) }\end{array}$ & $\begin{array}{l}\text { Lesion } \\
\text { level }\end{array}$ & $\begin{array}{l}\text { Years } \\
\text { post-injury }\end{array}$ & Medication & $\begin{array}{l}\text { Disordered } \\
\text { breathing }\end{array}$ \\
\hline 1 & 52 & 178 & 91 & $\mathrm{C} 5-\mathrm{C} 6$ & 2 & $\begin{array}{l}\text { Dilantin } \\
\text { Tegretol }\end{array}$ & Yes \\
\hline 2 & 70 & 178 & 73 & $\mathrm{C5}$ & 7 & $\begin{array}{l}\text { clonidine } \\
\text { Benadryl } \\
\text { Dilantin } \\
\text { baclofen } \\
\text { Macrodantin }\end{array}$ & Yes \\
\hline 3 & 46 & 169 & 81 & $\mathrm{C} 5-\mathrm{C} 6$ & 26 & $\begin{array}{l}\text { baclofen } \\
\text { Macrodantin }\end{array}$ & Yes \\
\hline 4 & 38 & 185 & 107 & T12-L1 & 19 & $\begin{array}{l}\text { Mellaril } \\
\text { Serax } \\
\text { lithium } \\
\text { Motrin }\end{array}$ & Yes \\
\hline $\mathrm{X}$ & $51 \cdot 5$ & $177 \cdot 5$ & 88 & & $13 \cdot 5$ & & \\
\hline
\end{tabular}

$\mathrm{X}$ : mean data

Table II Description of sleep apnea in 4 male SCI patients

\begin{tabular}{llllll}
\hline Patient & $\begin{array}{l}\text { Age } \\
\text { (years) }\end{array}$ & $\begin{array}{l}\text { Episodes of } \\
\text { desaturation } \\
(n<90 \%)\end{array}$ & $\begin{array}{l}\text { Duration of } \\
\text { longest apnea } \\
\text { (seconds) }\end{array}$ & $\begin{array}{l}\text { Lowest } \mathrm{O}_{2} \\
\text { saturation } \\
(\%)\end{array}$ & $\begin{array}{l}\text { TST } \\
\text { (minutes) }\end{array}$ \\
\hdashline 1 & 52 & 120 & 55 & 76 & 257 \\
2 & 70 & 60 & 75 & 61 & 253 \\
3 & 46 & 116 & 115 & 56 & 242 \\
4 & 38 & 26 & 55 & 77 & 325 \\
\hline
\end{tabular}

TST: total sleep time

Data on this group of SCI patients are summarised in Table I. All of the patients snored and had evidence of obstructive disordered breathing associated with $\mathrm{O}_{2}$ desaturation documented during nocturnal polysomnography (Table II). The 4 patients were overweight males, had a mean age of 51.5 years, and had stable 
spinal cord injuries for a mean of 13.5 years duration. Their obstructive disordered breathing was felt to be contributing to their sleep complaints. All were taking medications which also could be aggravating their obstructive disordered breathing at night. Two individuals were taking baclofen, which has been shown to cause drowsiness in up to $63 \%$ of patients. This medication may be additive to those effects of alcohol and other CNS depressants. Tegretol, Mellaril and Serax can also cause drowsiness.

Pulmonary function testing was performed on all patients. Patient 1 was an exsmoker and displayed an obstructive pattern $\left(\mathrm{FEV}_{1} / \mathrm{FVC}=61 \%\right)$. Patients 3 and 4 had a reduced forced vital capacity $(\mathrm{FVC}=79 \%$ and $60 \%$ of predicted, respectively), and patient 2 had normal spirometry. All 4 patients had awake baseline $\mathrm{O}_{2}$ saturations of 93 to $94 \%$.

Patient 4 was the youngest in the group, and represents an example of obstructive sleep apnea occurring almost exclusively during REM stage sleep in the supine position. Such patients with REM-induced apnea appear to have selective REM sleep fragmentation and often have obstructive breathing only in the supine position (Sullivan, 1985). Although our patient displayed only a little more than 5 apneas per hour, they were of significant duration and $\mathrm{O}_{2}$ desaturation to warrant proper therapy.

\section{Discussion}

Much has been written about the baseline pulmonary function, respiratory treatment and rehabilitation of patients with spinal cord injury. Pulmonary function tests in these patients are frequently abnormal, with reduction in the vital capacity and maximum breathing capacity. Bergofsky noted in 1964 that patients with a cervical cord injury have an alteration in their breathing mechanics because of the abnormally high extrapulmonary work of breathing attributable to the use of the diaphragm as the sole source of ventilation. This is frequently demonstrated clinically by paradoxical retraction of the ribcage. Decreased arterial oxygen tensions and elevated arterial carbon dioxide levels suggest that some of these patients also have chronic alveolar hypoventilation.

Unfortunately, practically nothing is written in the literature regarding sleep and respiration in these individuals. The only study which has looked at $\mathrm{O}_{2}$ saturation during sleep in patients with spinal cord injury was that of Braun and coworkers (1:82). They screened 11 stable patients with cervical and thoracic spinal cord lesions with nocturnal ear oximetry. Stage of sleep was not determined and they were studied for a mean of only 2.6 hours. The average age of the population studied was $29 \cdot 2$ years. They concluded that young quadriplegic patients do not have severe $\mathrm{O}_{2}$ desaturation during sleep, but older patients should be screened for sleep desaturation. Indeed, the 2 oldest patients in their series (aged 42 and 57 years) had several $\mathrm{O}_{2}$ desaturation episodes as low as $87 \%$ and $73 \%$ respectively. This shows that perhaps an older population of SCI patients may have more $\mathrm{O}_{2}$ desaturation related to disordered breathing while asleep. Again, this study did not attempt to characterise sleep stage nor was ribcage or abdominal motion observed. Therefore, information regarding whether many of these patients really went into deeper sleep or whether disordered breathing was a factor, cannot be determined. 
We do know of two observations which appear to characterise patients with high cervical transections during sleep: (1) these patients have a substantial increase in the amount of light sleep, and (2) there is an absolute and relative reduction in the amount of deep and REM stage sleep (Adey, 1968). This is important because studies (Adey, 1968; Agnew, 1964) have shown that loss of deep sleep may produce a depressed outlook, while REM deprivation may result in increased irritability

Table III Stages of sleep (\%) of 4 male SCI patients

\begin{tabular}{|c|c|c|c|c|c|c|c|}
\hline Patient & Awake & I & II & III & IV & REM & $\overline{M T}$ \\
\hline 1 & 21 & 17 & 31 & 6 & 1 & 23 & 1 \\
\hline 2 & 24 & 31 & 29 & 3 & 0 & 12 & 1 \\
\hline 3 & 7 & 28 & 29 & 0 & 0 & 18 & 18 \\
\hline 4 & 6 & 8 & 60 & 6 & 1.5 & 18 & 0.5 \\
\hline
\end{tabular}

MT: movement time

and lability. Table III shows the per cent of time that each of our 4 patients spent in various stages of sleep. NREM stage sleep is divided into 4 progressively deeper stages, and the deepest stages (stages III, IV) make up about $20 \%$ of total sleep time. About 20 to $25 \%$ of adult sleep is REM sleep. Our patients spent very little time in deep sleep and the amount of REM stage sleep was also less than what is present in normal subjects.

Although this study includes only a small group of patients, we conclude that sleep disordered breathing may be contributing to disruptive sleep in certain individuals in the SCI population. This disorder may be responsible for many of their daytime symptoms. Other symptoms including personality changes and mental deterioration have also been associated with sleep apnea. Obesity, sedative ingestion, and sleeping in the supine position are factors which may aggravate the situation. It is important to recognise obstructive disordered breathing in the SCI population as the disorder can be corrected and quality of life improved.

\section{References}

AdEy WR, Bors E, PORTER RW 1968 EEG sleep patterns after high cervical lesions in man. Archives of Neurology 19:377-383.

AGNEW HW, WEBB WB, WILliams RL 1964 The effects of stage four sleep deprivation. Electroencephalography and Clinical Neurophysiology 17:68-70.

Alvarez SE, PETERSON M, LUNSFORD BR 1981 Respiratory treatment of the adult patient with spinal cord injury. Physical Therapy 61:1737-1745.

BERGOFSKY EH 1964 Mechanism for respiratory insufficiency after cervical cord injury. A source of alveolar hypoventilation. Annals of Internal Medicine 61:435-447.

BRAUN SR, GIOVANNONI R, LEVIN AB, HARVEY RF 1982 Oxygen saturation during sleep in patients with spinal cord injury. American fournal of Physical Medicine 61:302-309.

INGBAR DH, GEE JBL 1985 Pathophysiology and treatment of sleep apnea. Annual Review of Medicine 36:369-395.

Kales A, Vela-Bueno A, Kales JD 1987 Sleep disorders: Sleep apnea and narcolepsy. Annals of Internal Medicine 106:434-443.

MORAN WB, ORR WC 1985 Diagnosis and management of obstructive sleep apnea. Archives of Otolaryngology 111:650-658.

Phillips BA, Okeson J, Paesani D, Gilmore R 1986 Effect of sleep position on sleep apnea and parafunctional activity. Chest 90:424-429.

Sullivan CE, IsSA FG 1985 Obstructive sleep apnea. Clinics in Chest Medicine 6:633-650.

SURATT PM, WILhoIt SC, BROWN ED, KAISER DL 1983 Correlation of sleep apnea severity indices. American Review of Respiratory Disease 127 (supplement): 106. 